\title{
Application of Taguchi Method and Grey Relational Analysis to Optimize the Solar Water Flat Plate Collector Processes
}

\author{
Brijendra Kumar Gond \\ Assistant professor, Mechanical Engineering \\ barkatullah University Bhopal, MP, India \\ Maheshwari Rahangdale, \\ Assistant professor, Mechanical Engineering \\ barkatullah University Bhopal, MP, India \\ Dr. Chandra Shekhar Malvi \\ Associate Professor, Mechanical Engineering, \\ Madhav Institute of Technology \& Science, Gwalior, MP, India
}

\begin{abstract}
This study also designed the processing parameters of the flat plate collector based on orthogonal arrays Processing parameters of a flat plate collector are the key factors affecting its performance. These parameters include the collector polymer tube material, copper plate material, number of collector polymer tubes, tube diameter, thickness of the bottom insulating material, iron tube with phase change material (PCM). The quality characteristics include the efficiency coefficient. After obtaining the data on each quality characteristic are obtained from the orthogonal arrays, main effect analysis and ANOVA (analysis of variance) are conducted to determine the parameters that have significant effects on these quality characteristics. The data are then preprocessed by grey relational generation, and the optimal combination of processing parameter levels is determined through grey relational analysis.
\end{abstract}

The optimal combination of the processing parameters is selected as A1, B2, C2, D2, E1, F2 and G1. The collector tube is made of iron, the plate is made of copper, the number of collector tubes is 6 , the collector tube diameter is $1 / 2$ inch, the absorption film type is Brush painting, and the thickness of the bottom heat insulating material is $1.5 \mathrm{~cm}$, and melting point of $P C M$ is $56^{\circ} \mathrm{C}$. So that the average values of the efficiency coefficients have been follow 0.787911 respectively. The overall quality can be effectively controlled by controlling the only parameter.

Keywords: - Taguchi method, Grey relational analysis, flat plate collector, phase change material (PCM), heat transfer, solar energy.

\section{INTRODUCTION}

Taguchi's method has become increasing popular as a method for developing engineered products. It promises, and delivers, an ability to increase the quality of an engineered product via simple changes in the method by which engineers perform their usual design tasks. Given the bold claims, there has been relatively little research in the design community on Taguchi's method: its foundations, assumptions, mathematics, techniques, and approximations. There has been little research to compare the technique to other methods, either analytically or experimentally, except for comparisons with experimental design techniques from which Taguchi's method is derived. In addition, there has been little research to attempt to improve the method itself. Proper design of solar water heating system is important to assure maximum benefit to the user, especially for a large system. Designing a solar hot water system involves appropriate sizing of different components based on predicted solar isolation and hot water demand[1].

All nations of the world depend on fossil fuels for their energy needs. However, the obligation to reduce $\mathrm{CO} 2$ and other gaseous emissions, in order to be in conformity with the Kyoto agreement is the reason behind which countries turn to non-polluting renewable energy sources [2]. An important issue in solar thermal system for industrial applications is the optimal sizing of the system i.e., appropriate sizing of the collectors, storage and heat exchanger [3].In recent years, some optimization methods that are conceptually different from the traditional mathematical programming techniques have been developed. These methods are labeled as modern 
or nontraditional methods of optimization. Most of these methods are based on certain characteristics and behavior of biological, molecular, swarm of insects, and neurobiological systems. Many practical optimum design problems are characterized by mixed continuous- discrete variables, and discontinuous and no convex design spaces. Taguchi's method is well suited for solving such problems, and in most cases they can find the global optimum solution with a high probability. The basic ideas of analysis and design based on the concepts of using Taguchi method, ANOVA (analysis of variance) \& grey relational are based on the principles of natural Taguchi and natural selection. The basic elements of natural Taguchi-reproduction, crossover, and mutation-are used in the Taguchi search procedure [4]. This paper presents the optimal sizing of solar thermal flat-plate collector system for an aquaculture system using Taguchi method also ANOVA (analysis of variance) \& grey relational is carried out.

A phase-change material (PCM) is a substance with a high heat of fusion which, melting and solidifying at a certain temperature, is capable of storing and releasing large amounts of energy. Heat is absorbed or released when the material changes from solid to liquid and vice versa; thus, PCMs are classified as latent heat storage (LHS) units. The thermal energy transfer occurs when a material changes from a solid to a liquid or from a liquid to a solid, this is called a change in state, or "phase". It absorbs a large amount of heat in the process of changing from solid to liquid phase and this result in cooling of the surroundings[5].

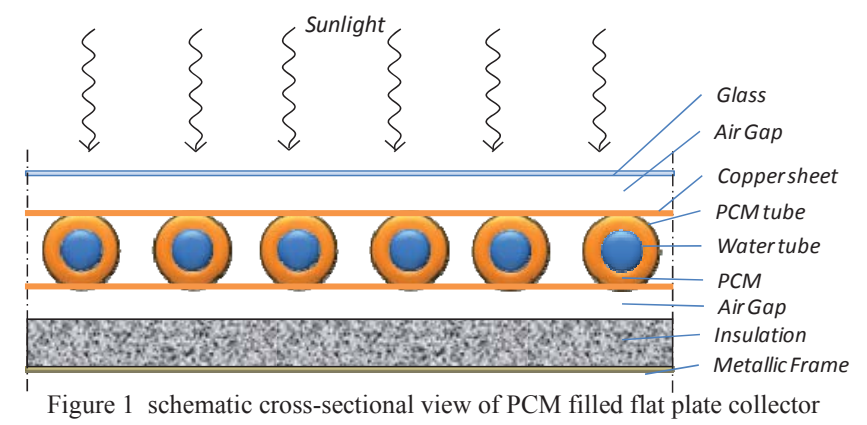

II. RESEARCH METHODS

\subsection{TAGUCHI METHOD}

Taguchi methods are statistical methods developed by Genichi Taguchi to improve the quality of manufactured goods, and more recently also applied to, engineering, biotechnology,[6,7] marketing and advertising.[8] Professional statisticians have welcomed the goals and improvements brought about by Taguchi methods, particularly by Taguchi's development of designs for studying variation, but have criticized the inefficiency of some of Taguchi's proposals.[9] The Taguchi method is used to design experiments based on the orthogonal arrays in order obtain the maximum amount of information with minimum experiments, Moreover, it can also analyze the experimental data based on the SN ratio. The quality characteristics of the flat-plate collector discussed in this study are efficiency coefficient factor. For flat-plate collectors, a higher efficiency coefficient is preferred. Therefore, the qualities characteristics of the efficiency coefficient are respectively the-larger-thebetter, which are defined as follows [10]:

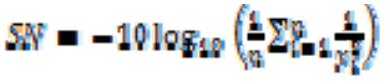

Where $y_{1}$ is a quality measurement; and $\mathrm{n}$ is the total of the measurements.

After experimental planning, the experiment is conducted to obtain the experimental data generated by the combination of various orthogonal parameters and a response graph is generated. First, the experimental data are calculated to acquire the SN ratio, and the calculation method depends on the requested quality characteristics. The average response value $\bar{\gamma}$ i of various factor levels is calculated, and then the main effect value $\Delta \mathrm{f}$ of various factor levels is calculated. These data are plotted into a response graph for the effect analysis of each factor. The higher the main effect value $\Delta \mathrm{f}$ of a factor, the greater the influence of the factor on the system, as compared to other factors. On the contrary, if the main affect value $\Delta \mathrm{f}$ of a factor is less than that of other factors, its quality improvement effect is not significant. The calculations can be expressed as below. 


$$
\begin{aligned}
& F i=\frac{k}{\mathrm{k}} \nabla_{i} W_{4} \eta_{\mathrm{i}}
\end{aligned}
$$

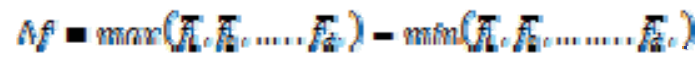

where $f_{1}$ is the mean SN ratio for the ith level of factor $\mathrm{f}, \mathrm{m}$ is the number of the I th level of each factor, $\eta_{j}$ is the $\mathrm{jth} \mathrm{SN}$ ratio of the ith level, and $\mathrm{d}$ is the number of the level of each factor.

\subsection{ANOVA (ANALYSIS OF VARIANCE)}

In statistics, analysis of variance (ANOVA) is a collection of statistics models, and their associated procedures, in which the observed variance in a particular variable is partitioned into components attributable to different sources of variation. In its simplest form ANOVA provides a statistics test of whether or not the means of several groups are all equal, and therefore generalizes t-test to more than two groups. Doing multiple twosample t-tests would result in an increased chance of committing a type I-error for this reason ANOVAs are useful in comparing two, three or more means.

The quality characteristics are evaluated through the SN ratio obtained in the Taguchi experimental plan, but the significance of each factor on the quality characteristics of the flat-plate collector. The main structure of the flatplate collectors unable to be obtained from the SN ratio. The ANOVA evaluates the experimental errors and test of significance to understand the effect of various factors. The method and equation of the ANOVA are as follows [11].

\subsection{1. $N$ (DEGREE OF FREEDOM)}

The DOF (degree of freedom) for each factor is the number of its level minus ONE. The total DOF is the number of the experiments minus ONE. The error of the DOF (ne) is the value of the total DOF minus the sum of the DOF of each factor.

\subsubsection{CF (CORRECTION FACTOR)}

$$
C F=\frac{\left(g_{n} n_{k}\right)^{2}}{n}
$$

Where $\eta$ the SN ratio of experimental observations and $\mathrm{n}$ is the number of the experiments

\subsubsection{SS (SUM OF SQUARE)}

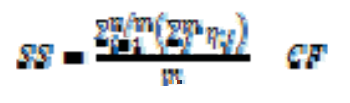

Where $\mathrm{m}$ is the number of each level of the factor

2.2.4. TSS (TOTAL SUM OF SQUARE)

$T S E=\Sigma M(n)^{2}-G F$

\subsubsection{SSE (ERROR SUM OF SQUARE)}

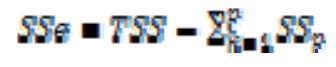

Where $\mathrm{p}$ is the number of the factor

When using saturated orthogonal array, there is no DOF for error. In other words, there is no error term, and the SSes is zero. In some experiments, all the factors may be highly significant; in other words, few factors may be significant. Therefore, it is necessary to use the pooling technique to estimate error; generally, pooling half the degrees of freedom in the orthogonal array experiment is recommended. 


\subsubsection{V(VARIANCE)}

It is the SS divided by the DOF.

$V=\frac{\pi i}{v}$

Ve (error mean sum of square) can be expressed as

Pe $=\frac{\text { SSe }}{w}$

\subsubsection{F (F-RATIO)}

It is the variance of each factor divided by the error variance.

$$
F=\frac{n}{n}
$$

\subsection{GREY RELATIONAL ANALYSIS}

In the analysis of the processing parameters of the flat-plate collector, an appropriate mathematic model is established in order to study the relationship between target values and the two quality characteristics of the flatplate collector obtained from the experiment. Its primary task is to analyze the difference between the quality characteristics of flat-plate collectors caused by various processing parameters, and understanding the relationship between the quality characteristics and target values.

Grey relational analysis is a method to measure the correlation degree between factors based on the similarity or difference between factors. It is characterized by less data and multifactor analysis, where these two characteristics can overcome the disadvantages of the statistical regression analysis. The procedure of the grey relational analysis is as follows $[12,13][14,15]$ :

Step 1: Grey relational generation; data preprocessing and calculation according to the quality characteristics.

The computing method of the grey relational generation is as follows:

(1) The-larger-the-better (in the event that the higher the target value, the better)

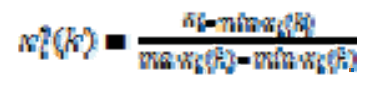

The useful energy of collector is given by

$$
Q_{w}=m C_{p f}\left(T_{h t}-T_{h n}\right)
$$

Where $\mathrm{m}$ is the flow rate of the water through the collector, $C_{p f}$ is the specific heat of the water $(4.185 \mathrm{kj} / \mathrm{kg}$ specific heat of water, $T_{f o}, T_{f i}$ are the outlet and inlet water temperature respectively[16].

The instantaneous efficiency coefficient of collector is given by

$$
\text { meff }=\frac{p h}{A_{p} R}
$$

Where $A_{c}$ is the collector area and I $(t)$ is the Illumination intensity of the collector $(\mathrm{W} / \mathrm{m} 2)$. Putting the all value water flow rate of the, specific heat, outlet and inlet water temperature, and collector area or Illumination intensity of this formula get the useful data, average and efficiency of coefficient due to the my project are completed 


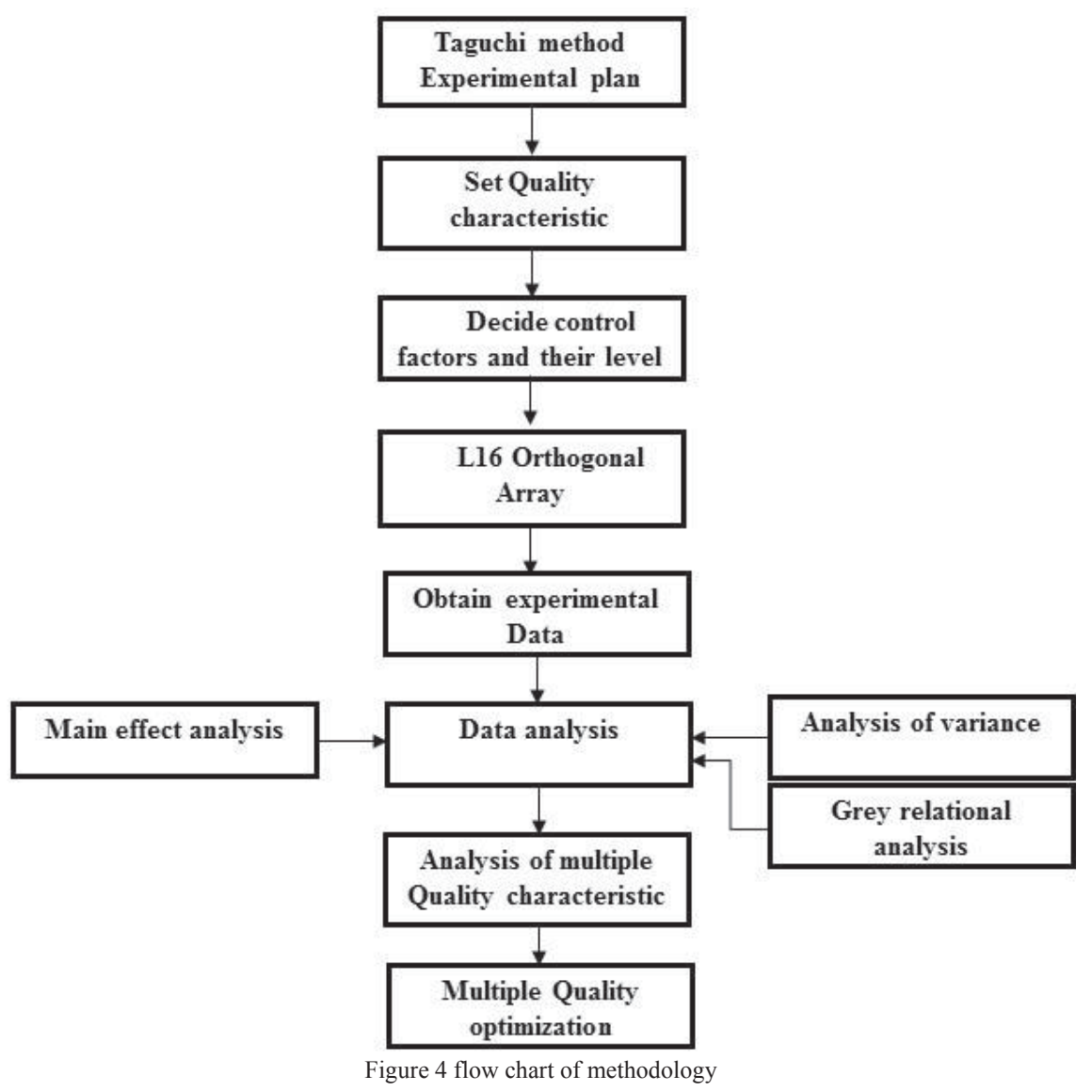

Table 1 Controlling factors of the flat-plate collector and their levels

Controlling factor

Level value

1

A. Collector tube material

(A1) flexible (A2) Iron tube

B. Endothermic plate material

(B1) Aluminum

(B2) Copper

C. Number of collector tubes (piece)

(C1) 6

(D1) $1 / 4$

(C2) 11

D. Collector tube diameter (inch)

(E1) Brush painting (E2) Hand painting

F. Thickness of the bottom heat

Insulating material (cm)

(F1) 1

(F2) 1.5

G. Phase Change Material (PCM) $\left({ }^{\circ} \mathrm{C}\right)$

(G1) $56 \quad$ (G2) 46

Interference factor

Table 2 Interference factors of the flat-plate collector and their levels. Level value 2 3

P Illumination intensity $(\mathrm{W} / \mathrm{m} 2)$

(p1) 800

(p2) 900

(p3) 1000

q Temperature $\left({ }^{\circ} \mathrm{C}\right)$

(q1) 25

(q2) 35

(q3) 45 


\begin{tabular}{|c|c|c|c|c|c|c|c|c|}
\hline S.N & A & B & $\mathrm{C}$ & D & $\mathrm{E}$ & $\mathrm{F}$ & $\mathrm{G}$ & 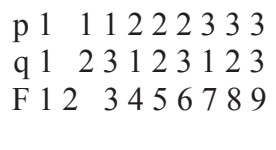 \\
\hline 1. & 1 & 1 & 1 & 1 & 1 & 1 & 1 & \\
\hline 2. & 1 & 1 & 1 & 2 & 1 & 2 & 2 & \\
\hline 3. & 1 & 1 & 2 & 1 & 2 & 1 & 2 & \\
\hline 4. & 1 & 1 & 2 & 2 & 2 & 2 & 1 & \\
\hline 5. & 1 & 2 & 1 & 1 & 2 & 2 & 1 & \\
\hline 6. & 1 & 2 & 1 & 2 & 2 & 1 & 2 & \\
\hline 7. & 1 & 2 & 2 & 1 & 1 & 2 & 2 & \\
\hline 8. & 1 & 2 & 2 & 2 & 1 & 1 & 1 & \\
\hline 9. & 2 & 1 & 1 & 1 & 2 & 2 & 2 & \\
\hline 10 . & 2 & 1 & 1 & 2 & 2 & 1 & 1 & \\
\hline 11. & 2 & 1 & 2 & 1 & 1 & 2 & 1 & \\
\hline 12. & 2 & 1 & 2 & 2 & 1 & 1 & 2 & \\
\hline 13. & 2 & 2 & 1 & 1 & 1 & 1 & 2 & \\
\hline 14. & 2 & 2 & 1 & 2 & 1 & 2 & 1 & \\
\hline 15. & 2 & 2 & 2 & 1 & 2 & 1 & 1 & \\
\hline 16. & 2 & 2 & 2 & 2 & 2 & 2 & 2 & \\
\hline
\end{tabular}

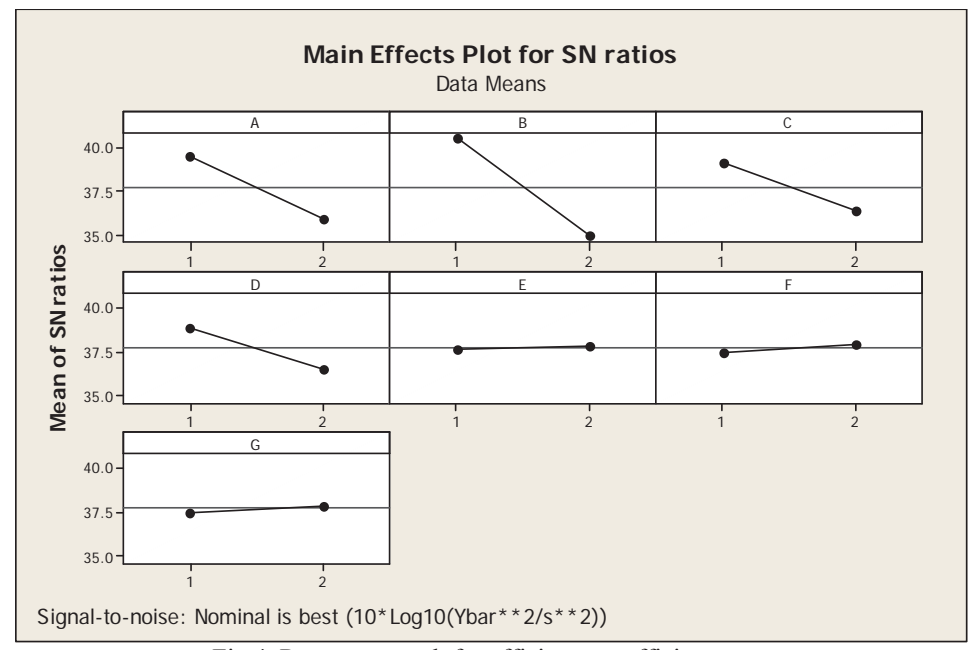

Fig.4. Response graph for efficiency coefficient

Table 4 The ANOVA of efficiency coefficient

\begin{tabular}{lcccccc}
\hline Source & DOF & $\begin{array}{c}\text { Sum of } \\
\text { Square }\end{array}$ & Variance & F-ratio & pure sum of square & $\begin{array}{c}\text { Percentage of } \\
\text { contribution }\end{array}$ \\
\hline A & 1 & 0.3333 & 0.5333 & - & - & - \\
B & 1 & 9.5445 & 6.2723 & 19.9013 & 11.0400 & 55.74 \\
C & 1 & 4.3904 & 2.6952 & 5.7204 & 3.8859 & 17.45 \\
D & 1 & 0.3562 & 0.2281 & - & - & - \\
E & 1 & 1.0263 & 0.5131 & 2.0343 & 0.5218 & 5.79 \\
F & 1 & 1.5520 & 0.7260 & 3.8781 & 0.8475 & - \\
G & 1 & 2.3780 & - & - & - & - \\
Error & 9 & 2.3807 & - & - & - & 25.95 \\
Pooled error & 4 & 2.4702 & 0.2522 & - & 7.2882 & 100.00 \\
Total & 16 & 17.6834 & - & - & 19.6834 & - \\
\hline
\end{tabular}


Table 5 Test Result of the Efficiency Coefficient

\begin{tabular}{|c|c|c|c|c|c|c|c|c|c|c|c|}
\hline S.No. & 1 & 2 & 3 & 4 & 5 & 6 & 7 & 8 & 9 & Average & \begin{tabular}{|l|} 
S/N \\
Ratio \\
\end{tabular} \\
\hline 1 & 0.792251 & 0.783641 & 0.781739 & \begin{tabular}{|l|l|}
0.789675 \\
\end{tabular} & \begin{tabular}{|l|l|}
0.785941 \\
\end{tabular} & \begin{tabular}{|l}
0.784949 \\
\end{tabular} & \begin{tabular}{|l|l|}
0.780656 \\
\end{tabular} & 0.786606 & 0.780812 & \begin{tabular}{|l|l|}
0.785141 \\
\end{tabular} & -4.73272 \\
\hline 2 & 0.795402 & 0.78244 & 0.787396 & \begin{tabular}{|l|}
0.78909 \\
\end{tabular} & 0.778882 & 0.779556 & \begin{tabular}{|l|l}
0.782359 \\
\end{tabular} & 0.781408 & 0.780812 & \begin{tabular}{|l}
0.784149 \\
\end{tabular} & -4.74237 \\
\hline 3 & 0.793408 & 0.795166 & 0.787396 & 0.786668 & 0.790979 & 0.78859 & 0.781337 & 0.78285 & 0.780955 & \begin{tabular}{|l|l|}
0.787483 \\
\end{tabular} & -4.6838 \\
\hline 4 & \begin{tabular}{|l}
0.793408 \\
\end{tabular} & 0.795555 & 0.784053 & \begin{tabular}{|l|l|}
0.792892 \\
\end{tabular} & \begin{tabular}{|l|l|}
0.779052 \\
\end{tabular} & 0.792618 & \begin{tabular}{|l|l|}
0.786785 \\
\end{tabular} & \begin{tabular}{|l|l|}
0.78522 \\
\end{tabular} & 0.78155 & \begin{tabular}{|l|}
0.787904 \\
\end{tabular} & -4.68367 \\
\hline 5 & 0.643861 & 0.640327 & 0.673112 & 0.663963 & 0.672929 & 0.672803 & 0.658061 & 0.671172 & 0.685643 & 0.664652 & -6.20743 \\
\hline 6 & 0.770702 & 0.775593 & 0.770448 & \begin{tabular}{|l|l|}
0.767234 \\
\end{tabular} & 0.771727 & 0.740705 & \begin{tabular}{|l|l|}
0.764868 \\
\end{tabular} & \begin{tabular}{|l}
0.749988 \\
\end{tabular} & 0.748359 & \begin{tabular}{|l|l|}
0.762181 \\
\end{tabular} & -4.94414 \\
\hline 7 & \begin{tabular}{|l|l|}
0.78339 \\
\end{tabular} & \begin{tabular}{|l}
0.768546 \\
\end{tabular} & 0.764107 & \begin{tabular}{|l|l|}
0.758034 \\
\end{tabular} & \begin{tabular}{|l|l|}
0.76153 \\
\end{tabular} & 0.760079 & \begin{tabular}{|l|l|}
0.778427 \\
\end{tabular} & 0.787842 & 0.766162 & \begin{tabular}{|l|l|}
0.769791 \\
\end{tabular} & -4.93079 \\
\hline 8 & 0.68104 & 0.669438 & 0.663956 & 0.663963 & 0.656405 & 0.647365 & 0.641099 & 0.648598 & 0.661983 & 0.659316 & -6.23153 \\
\hline 9 & 0.743796 & \begin{tabular}{|l|l|}
0.746707 \\
\end{tabular} & 0.746283 & \begin{tabular}{|l|l|}
0.755548 \\
\end{tabular} & \begin{tabular}{|l|l|}
0.747924 \\
\end{tabular} & 0.751141 & \begin{tabular}{|l|l|}
0.752699 \\
\end{tabular} & 0.746691 & 0.752013 & 0.7492 & \begin{tabular}{|l|l|}
-5.13077 \\
\end{tabular} \\
\hline 10 & 0.708199 & \begin{tabular}{|l}
0.712687 \\
\end{tabular} & \begin{tabular}{|l}
0.70247 \\
\end{tabular} & 0.721117 & 0.729835 & 0.734542 & \begin{tabular}{|l}
0.713837 \\
\end{tabular} & 0.726663 & 0.702479 & 0.71687 & -5.52336 \\
\hline 11 & 0.787139 & 0.776867 & 0.768806 & \begin{tabular}{|l|l|}
0.769784 \\
\end{tabular} & \begin{tabular}{|l|l|}
0.788857 \\
\end{tabular} & 0.752911 & \begin{tabular}{|l|l|}
0.751069 \\
\end{tabular} & 0.754319 & 0.754345 & \begin{tabular}{|l|l|}
0.767122 \\
\end{tabular} & \begin{tabular}{|l|}
-4.91069 \\
\end{tabular} \\
\hline 12 & 0.746765 & \begin{tabular}{|l}
0.745261 \\
\end{tabular} & 0.756904 & \begin{tabular}{|l|l|}
0.746457 \\
\end{tabular} & \begin{tabular}{|l|l|}
0.739963 \\
\end{tabular} & \begin{tabular}{|l}
0.729984 \\
\end{tabular} & \begin{tabular}{|l|l|}
0.717547 \\
\end{tabular} & 0.716142 & 0.706597 & \begin{tabular}{|l|l|}
0.733958 \\
\end{tabular} & -5.25369 \\
\hline 13 & 0.789714 & 0.78958 & 0.771809 & 0.756042 & 0.764627 & 0.757229 & 0.764868 & 0.768912 & 0.753075 & 0.768428 & -4.89007 \\
\hline 14 & \begin{tabular}{|l|l|}
0.7648 \\
\end{tabular} & \begin{tabular}{|l|l|}
0.767258 \\
\end{tabular} & 0.764107 & \begin{tabular}{|l|l|}
0.74151 \\
\end{tabular} & \begin{tabular}{|l|l|}
0.755203 \\
\end{tabular} & \begin{tabular}{|l}
0.760079 \\
\end{tabular} & \begin{tabular}{|l|l|}
0.748684 \\
\end{tabular} & $\mathbf{0 . 7 4 3 8 3 7}$ & 0.751291 & \begin{tabular}{|l|l|}
0.755196 \\
\end{tabular} & \begin{tabular}{|l|l|} 
\\
\end{tabular} \\
\hline 15 & 0.752535 & \begin{tabular}{|l|l|}
0.752401 \\
\end{tabular} & 0.73463 & \begin{tabular}{|l|l|}
0.739519 \\
\end{tabular} & 0.731579 & 0.724181 & \begin{tabular}{|l}
0.735125 \\
\end{tabular} & 0.724297 & 0.723332 & \begin{tabular}{|l}
0.735289 \\
\end{tabular} & -5.26918 \\
\hline 16 & 0.715356 & 0.733812 & 0.71604 & 0.722995 & 0.715055 & 0.691133 & 0.675639 & 0.694554 & 0.663846 & 0.703159 & -5.58854 \\
\hline
\end{tabular}

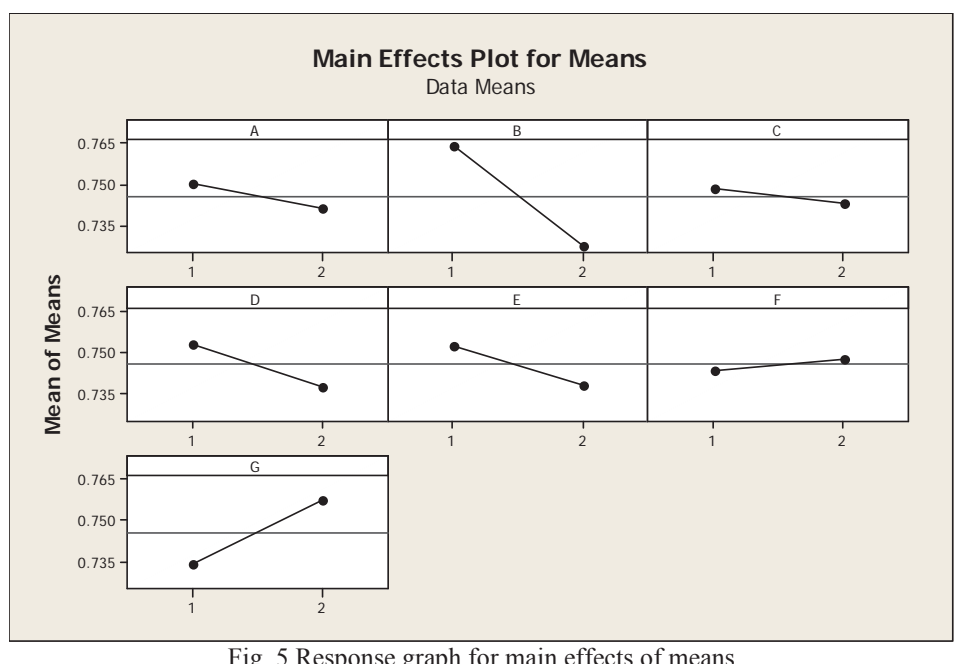

Fig. 5 Response graph for main effects of means

\section{RESULTS AND DISCUSSION}

\section{3. (a) EXPERIMENTAL PLAN}

This study discussed the relationship between the design processing parameters and quality characteristics of flat-plate collectors, in order to determine the optimized combination of processing parameters. First, the composition of various controlling factors, interference factors, and level values are designed based on the Taguchi method, as shown in Tables 1 and 2. Flat-plate collectors have quality characteristics, efficiency coefficient factor. As a flat-plate collector requires a higher efficiency coefficient factor, this study selected the efficiency coefficient as the-larger-the-better. Based on the required quality characteristics, the level values of controlling factors and interference factors are respectively applied to the L16 $(2 * 7)$ orthogonal array as the planning form of the experiment, as shown in Table 3. The performance of the flat-plate collector is calculated based on the Minitab software, which is developed with the numerical model established according to the experimental plan and the test standard ASHRAE (American Society of Heating, Refrigerating and AirConditioning Engineers). Followed by 16 groups of experiments, the data of each quality characteristic are collected, and the data of a total 144 experiments are obtained. The SN ratio for each group in the experiments is calculated according to the experimental data. 
The experimental data of the efficiency coefficient of the flat plate collector are shown in Table 4 Based on the SN ratios obtained through the experiments, the main effects of each control factor can be calculated, and its response graph can be plotted. The calculation of the main effects of each controlling factor aims at analyzing the influence of each factor at different levels on the SN ratios of quality characteristics; hence, the total influencing effect of each level of each controlling factor on the efficiency coefficient needs to be calculated. The factor response graph shows that the optimal factor levels are selected as A1, B2, C2, D2, E1, F2, and G1. The collector tube is made of iron, the endothermic plate is made of copper, the number of collector tubes is 6 , the collector tube diameter is $1 / 2$ inches, the absorption film type is Brush painting, and the thickness of the bottom heat insulating material is $1.5 \mathrm{~cm}$ and malting point of $\mathrm{PCM}$ is $56^{\circ} \mathrm{C}$. As shown in the response graph, the controlling factor B has the maximum influence on the efficiency coefficient, followed by A, C, D, F, G, and $\mathrm{E}$ in sequence.

\section{3 (c) MULTIPLE QUALITY OPTIMIZATIONS}

The above result analysis shows that an optimized combination of the efficiency coefficients is A1, B2, C2, D2, E1, F2, and G1. The optimized combinations of quality characteristics are different, and therefore, a truly optimized combination of processing parameters of the overall quality characteristics of the flat plate collector cannot be obtained; instead, it is obtained based on the grey relational analysis. Based on the main effect analysis, multiple quality characteristic problems are discussed, and the response graph is generated, as shown in Fig. 4. The optimal combination of the processing parameters is selected as A1, B2, C2, D2, E1, and F2, G1. The collector tube is made of iron, the endothermic plate is made of copper, the number of collector tubes is 11 , the collector tube diameter is $1 / 2$, the absorption film type is Brush painting, and the thickness of the bottom heat insulating material is $1.5 \mathrm{~cm}$ and malting point of PCM is $56^{\circ} \mathrm{C}$. The flat-plate collector body is made based on the obtained optimized combination of the design levels of multiple quality parameters. The performance test equipment used for the flat-plate collector body in this study is shown in Fig.6. The performance test equipment is a closed-liquid test system.

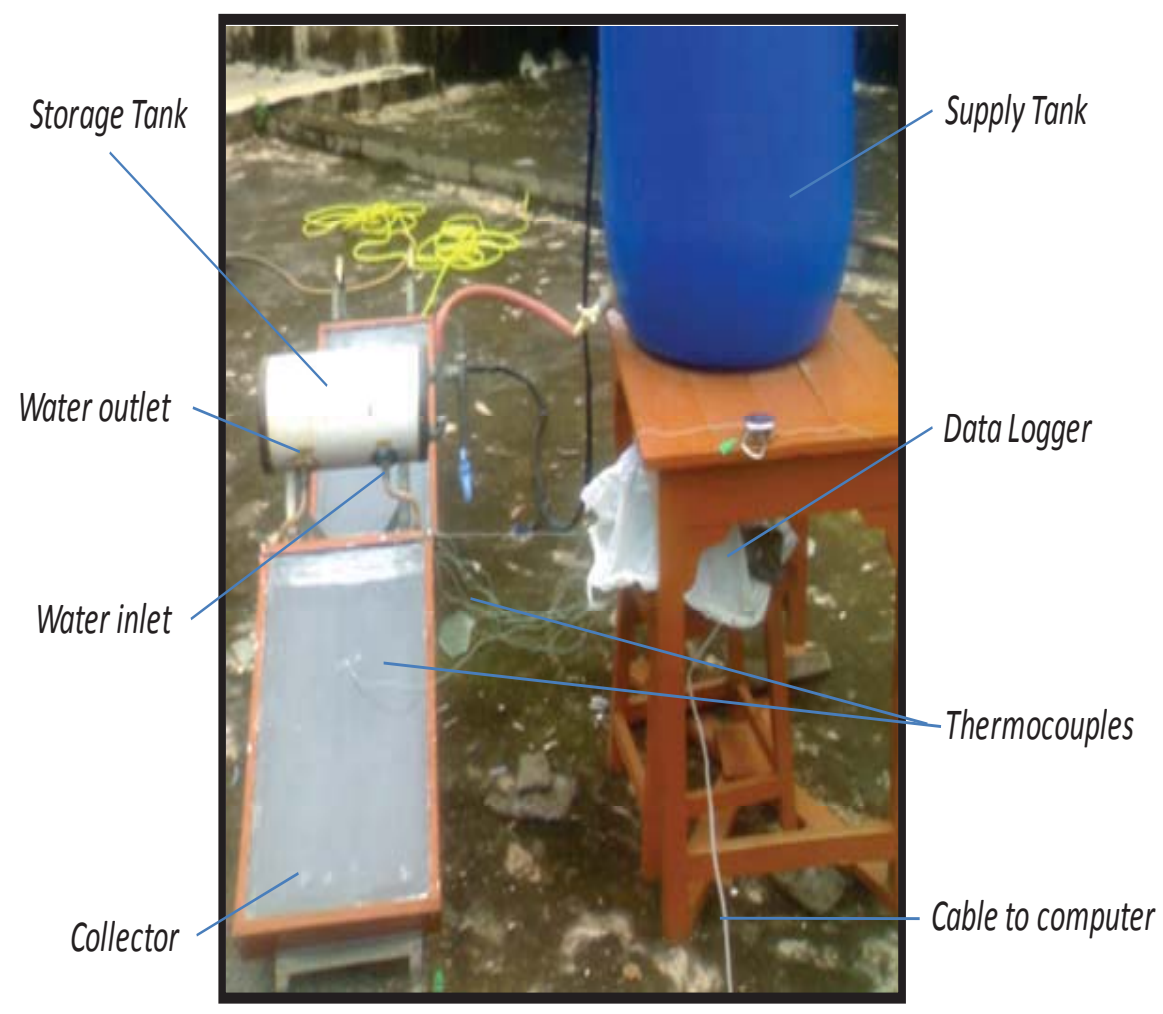

Fig.6. Experimental set up of PCM-flat plate collector body. 


\section{CONCLUSION}

This study attempted to optimize the processing parameters and achieve the optimal performance of flat-plate collector. By using the Taguchi method for experimental planning, the experimental time and costs were greatly reduced. Grey relational analysis is used to overcome the disadvantages of the Taguchi method in multiple quality analysis. The optimal combination of processing parameters was determined based on the main effect analysis. The optimal combination of the factor level parameters and the optimal performance of the multiple quality flat-plate collectors were also obtained. Three confirmatory tests proved that the average values of the efficiency coefficients are 0.787911 respectively. Their SN ratios fall within the $93 \% \mathrm{CI}$, proving that the test is reliable and repeatable. The optimal combination of multiple quality characteristic parameters is that The collector tube is made of iron, the endothermic plate is made of copper, the number of collector tubes is 11 , the collector tube diameter is $1 / 2$, the absorption film type is Brush painting, and the thickness of the bottom heat insulating material is $1.5 \mathrm{~cm}$ and malting point of PCM is $56^{\circ} \mathrm{C}$. Additionally, the ANOVA indicates that the absorption membrane type is a significant factor that affects the overall quality of the flat-plate collector. The contribution percentage of the pooled error is less than $40 \%$, showing that the important factors can be effectively controlled in the experiment, and the test result has a good accuracy. However, in this study, the efficiency coefficient is respectively 0.787911 under optimal conditions. The efficiency of this optimization model had been successfully proven by experiments, and can fulfill the research purpose of waste prevention.

\section{FUTURE SCOPE}

Further research will involve testing to measure problems associated with PCM filling in panels. The work involves testing various other assembly methods, such as making the design cheaper by taking out the SFPC.In the future the optimization model will be further applied to the planning of other related processes as a point of reference for them.

\section{REFERENCES}

[1] Malvi, C.S., D.W. Dixon-Hardy, and R. Crook, Energy balance model of combined photovoltaic solar-thermal system incorporating phase change material. Solar Energy, 2011. 85(7): p. 1440-1446.

[2] B.K. Gond, M.K. Gaur, C.S. Malvi, "Manufacturing and Performance Analysis of Solar Flat Plate Collector with Phase Change Material "Solar Energy Vol. 2 Issue 3, PP. 2250-2459, march 2012.

[3] Govind N. Kulkarni, Shireesh B. Kedare, Santanu Bandyopadhyay,"Determination ofdesign space and optimization of solar water heating systems," Solar Energy, Vol. 81, PP. 958-968, 2007.

[4] Soteris Kalogirou, "Thermal performance, economic and environmental life cycle analysis of thermosiphon solar water heaters," Solar Energy,Vol. 83, PP. 39-48, 2009.

[5] Govind N. Kulkarni, Shireesh B. Kedare, Santanu Bandyopadhyay, "Design of solar thermal systems utilizing pressurized hot water storage.

[6] Singiresu S. Rao, Engineering Optimization, Theory and Practice, Fourth Edition, John Wiley \& Sons, Inc., Hoboken, New Jersey, Canada,2009.

[7] Mohsen, M.S., A. Al-Ghandoor, and I. Al-Hinti, Thermal analysis of compact solar water heater under local climatic conditions. International Communications in Heat and Mass Transfer, 2009. 36(9): p. 962-968.

[8] Kurt O'Ferrall, L., General thermal analysis of serpentine-flow flat-plate solar collector absorbers. Solar Energy, 1989. 42(2): p. 133142 .

[9] Reiff F, Roses M, Venczel L, Quick R, Will V. Low cost safe water for the world: a practical interim solution. Health Policy1996;17:389-408.

[10] T aylor PB. Energy and thermal performance in the residential sector: Chapter 8 Developing a new low cost solar water heater (Thermal Problem 3); PhD dissertation; Potchefstroom University, Potchefstroom, 2001. p. 159-94.

[11] Zingano BW. A discussion on thermal comfort with reference to bath water temperature to deduce a midpoint of the thermal comfort temperature zone. Renewable Energy 2001;23:41-7.

[12] Yeh HM, Ho CD, Yeh CW. Effect of aspect ratio on the collector efficiency of sheet-and-tube solar water heaters with the consideration of hydraulic dissipated energy. Renew Energy 2003;28:1575e86.

[13] Eisenmann W, Vajen K, Ackermann H. On the correlations between collector efficiency factor and material content of parallel flow flat-plate solar collectors. Sol Energy 2004;76:381e7.

[14] Farahat S, Sarhaddi F, Ajam H. Exergetic optimization of flat plate solar collectors. Renew Energy 2009;34:1169e74.

[15] Liu WL, Hsieh SH, Chen WJ, Wei PI, Lee JH. Synthesis of the CuInSe2 thin film for solar cells using the electrodeposition technique and Taguchi method. Int J Miner Metall Mater 2009;16:101e7.

[16] Jun SI, McKnight TE, Simpson ML, Rack PD. A statistical parameter study of indium tin oxide thin films deposited by radiofrequency sputtering. Thin Solid Films 2005;476:59e64.

[17] Tiwari G.N. "fundamentals, design, modeling and applications" solar energy Vol. 8, p.p. 1-510. 